\begin{tabular}{|l|l|l|}
\hline \multicolumn{2}{|c|}{ PublisherInfo } \\
\hline \hline PublisherName & $:$ & BioMed Central \\
\hline \hline PublisherLocation & $:$ & London \\
\hline \hline PublisherImprintName & $:$ & BioMed Central \\
\hline \hline
\end{tabular}

\title{
Longevity gene identified
}

\begin{tabular}{|l|l|l||}
\hline \multicolumn{2}{|c|}{ ArticleInfo } \\
\hline \hline ArticleID & $:$ & 4769 \\
\hline \hline ArticleDOI & $:$ & $10.1186 /$ gb-spotlight-20030509-01 \\
\hline \hline ArticleCitationID & $:$ & spotlight-20030509-01 \\
\hline \hline ArticleSequenceNumber & $:$ & 121 \\
\hline \hline ArticleCategory & $:$ & Research news \\
\hline ArticleFirstPage & $:$ & 1 \\
\hline \hline ArticleLastPage & $:$ & 2 \\
\hline \hline & & RegistrationDate : 2003-5-9 \\
\hline ArticleHistory & $:$ & OnlineDate \\
\hline \hline ArticleCopyright & $:$ & BioMed Central Ltd2003-5-9 \\
\hline \hline ArticleGrants & $:$ & \\
\hline \hline ArticleContext & $:$ & 130594411 \\
\hline \hline
\end{tabular}




\section{Cathy Holding}

Email: cholding@hgmp.mrc.ac.uk

Restriction of calorie intake increases lifespan in many organisms, including mammals, and is mediated by gene silencing at telomere and rDNA loci through the activity of a nicotinamide adenine dinucleotide $\left(\mathrm{NAD}^{+}\right)$-dependent histone deactylase, Sir2. NAD is produced either de novo, or by recycling NAD degradation products in the salvage pathway, where nicotinamide is the starting point. It has been unclear if increasing NAD levels activate Sir2, or decreasing levels of nicotinamide relieve the inhibition of Sir2. In May 8 Nature, Rozalyn Anderson and colleagues at Harvard Medical School, Boston, further address the issue in yeast by focusing on the nicotinamide cleaving enzyme, $P N C 1$ (Nature 423:181-185, May 8, 2003).

Anderson et al. used deletion mutants to demonstrate that $P N C l$ is necessary for the beneficial effects of calorie restriction (CR) and that additional copies of the gene dramatically increase lifespan. They created a $P N C 1$ and SIR2 double deletion mutant and showed that these gene products function in the same pathway. Unlike SIR2, which is not induced by CR, $P N C 1$ levels were increased by all conditions known to cause extended lifespan in yeast, and nicotinamide hydrolysis also increased. Their observation that a $\mathrm{PNCl}$-GFP fusion protein was concentrated into cytoplasmic foci counters previous theories that the NAD salvage pathway occurs predominantly in the nucleus, a theory used to explain the absence of a measurable increase in NAD in CR. In addition, they showed that $\mathrm{PNCl}$ was localized to peroxisomes.

"These findings raise the possibility that nicotinamide regulates critical cellular processes in higher organisms," conclude the authors.

\section{References}

1. Nicotinamide adenine dinucleotide, a metabolic regulator of transcription, longevity and disease.

2. Inhibition of silencing and accelerated aging by nicotinamide, a putative negative regulator of yeast Sir2 and human SIRT1.

3. Nature, [http://www.nature.com/nature/]

4. Harvard Medical School, [http://www.hms.harvard.edu/] 